\title{
Golovinomyces bolayi causes powdery mildew on Persian speedwell (Veronica persica) in Iran
}

\author{
Hadi Golmohammadi ${ }^{1}$ - Mohsen Torbati ${ }^{1}$ • Mahdi Arzanlou ${ }^{1}$ \\ Received: 21 January 2019 / Accepted: 1 July 2019 / Published online: 9 July 2019 \\ (C) Australasian Plant Pathology Society Inc. 2019
}

\begin{abstract}
During October-November of 2017 and 2018, powdery fungal masses were observed on leaves of Persian speedwell (Veronica persica) on the campus of Tabriz University, East Azerbaijan Province, Iran. Infected leaves were collected and subjected to a taxonomic study. Based on morphological characteristics the fungus was identified as Golovinomyces orontii species complex. A phylogeny inferred based on ITS-rDNA sequence data clustered our isolate as Golovinomyces bolayi. Golovinomyces bolayi has recently been segregated from the Golovinomyces orontii species complex. Golovinomyces bolayi can be differentiated from other closely related species based on morphological characteristics of conidiophores and ITS-rDNA phylogeny. This is the first report of this species from Iran on Persian speedwell.
\end{abstract}

Keywords ITS-rDNA · Golovinomyces orontii · Persian speedwell · Phylogeny

Persian speedwell (Veronica persica) is a widespread small annual weed with a blue flower in the family Plantaginaceae. The genus Veronica comprises some 60 species, 18 of which are endemic to Iran (Saeidi-Mehrvarz and Zarrei 2006). Powdery mildews are common and widespread diseases of plant species, including Veronica spp., worldwide. Golovinomyces spp. and Podosphaera fuliginea have been reported as the causal agents of powdery mildew disease on some of the species in the genus Veronica (Braun and Cook 2012). Until the present, there have been two reports of powdery mildew on $V$. persica caused by G. orontii from Korea and Switzerland, respectively and a single report on the occurrence of Podosphaera fuliginea on this host in Argentina (Braun and Cook 2012). In the current study, we report a new powdery mildew disease on $V$. persica from Iran. During October-November in two successive years (2017-2018), infected leaves of $V$. persica growing in the lawn campus at University of Tabriz (East Azerbaijan Province, Iran) were observed to be covered by white powder-like fungal masses. Infected leaves were collected in a paper bag and subjected to taxonomic

Mahdi Arzanlou

Arzanlou@hotmail.com; Arzanlou@ tabrizu.ac.ir

1 Plant Protection Department, Faculty of Agriculture, University of Tabriz, P.O. Box 5166614766, Tabriz, Iran analysis. Fresh fungal structures were mounted in distilled water and examined at $(\times 1,000$ magnification) using an Olympus BX41 light microscope. At least 30 measurements were made for each microscopic structure where possible and 95 confidence intervals were calculated for the measurements with the extremes given in parentheses. An Olympus digital camera system (DP 25) was used to capture high-resolution photographs of microscopic fungal structures. Dried specimens were deposited in the Fungal Herbarium of the Iranian Research Institute of Plant Protection (IRAN 17161F).

Total fungi DNA was extracted from fungal hyphae and conidia by the protocol of Arzanlou et al. (2018). Briefly, under stereomicroscope a small patch of fresh and newly developed fungal powdery mass from the abaxial leaf surface was picked up using a sterile inoculation needle and dipped into PCR tubes containing $50 \mu \mathrm{TE}$ buffer, then crushed with sterile pipette tip. Following this stage, heated at $95{ }^{\circ} \mathrm{C}$ for 5 min with the PCR machine. DNA was stored at $-20{ }^{\circ} \mathrm{C}$ for further uses. Universal set primers ITS1 ( $5^{\prime}$-TCCGTA GGTGAACCTGCGG- $3^{\prime}$ ) and ITS4 (5'-TCCTCCGC TTATTGATATGC-3') were used to amplify parts of the rDNA internal transcribed spacer region (ITS15.8S-ITS2) using polymerase chain reaction (White et al. 1990). The reaction mixture and PCR cycling conditions used were the same at Arzanlou et al. (2018). PCR products were subjected to electrophoresis in $1 \%$ agarose gel in $1 \mathrm{X}$ TAE buffer. The amplicons were sequenced by the Pishgam Biotech Company 
in Iran, with the same primers set for PCR. Raw sequence files were edited by Sequencher 5.4.6 (Gene Codes, Ann Arbor, MI, USA) and subjected to BLAST search against the nucleotide sequence data at GenBank for similarity match. The alignments were observed visually and a minimum number of gaps were inserted in order to improve the alignment. Bayesian analyses were accomplished in PAUP v.4.0b10 and MrBayes v3.2.2 (Ronquist and Huelsenbeck 2003). The best-fitting evolutionary model was estimated by using Mrmodeltest v.2.2 (Nylander 2004). Arthrocladiella mougeotii (AB077621) was used as out group taxon. The generated phylogenetic tree was visualized in FigTree version 1.4.3. The sequence obtained in this study was deposited into GenBank with the accession number MK601682.

All of the Persian speedwell plants from sampling sites were infected with powdery mildew disease. Signs of the disease were commonly observed on leaves. Whitish mycelia were present as evanescent to persistent, irregular, distinct, scattered spots, predominantly on the upper leaf surface; later thin and effuse colonies developed on the lower side of the leaves (Fig. 1). Chasmothecia were not observed in the two successive years. The hyphae were amphigenous, branched, septate, hyaline, thin-walled, and smooth with 4-8 $\mu \mathrm{m}$ wide in patch or effuse. Appressoria on the mycelium were poorly developed to nipple-shaped, solitary, 3-4.5 $\mu \mathrm{m}$ diam. Conidiophores arising from superficial hyphae, on upper surface of mother cells or lateral, central or usually somewhat towards one septum of the mother cells, to slightly lateral, $(62.5-) 111.5-133.5(-197) \times(10-) 12-13(-12.5) \mu \mathrm{m}$ diam. Foot cells straight or curved at basal part, occasionally curved to sinuous throughout, cylindrical, basal septum at junction with supporting hyphae or slightly upper, usually not constricted at basal septum (Fig. 1e), followed by 2-3 shorter cells, (50-)94.5-117(-150) × (8-)10-11.5(-13) $\mu \mathrm{m}$ diam. Conidia ellipsoid to ovate, doliiform, formed in the chain with 1-7, hyaline, smooth, lake fibrosin bodies, $(25-) 32-36(-47.5) \times(12.5-) 15-16(-20) \mu \mathrm{m}$ diam. Germ tubes were produced on the perihilar position on conidia (Euoidium type) (Fig. 1). Based on the morphological characters the fungus was identified of the conidial stage of the genus Golovinomyces orontii. Golovinomyces orontii is a heterogenous complex with broad host range (Takamatsu et al. 2013). According to morphological features $G$. orontii is closely related with $G$. cichoracearum-like powdery mildew occurring on Cichorioideae (Braun and Cook 2012; Matsuda and Takamatsu 2003). Also, in G. cichoracearum appressoria is a different shape and chasmothecia are produced commonly on the host (Braun and Cook 2012). A very recent phylogenetic and morphotaxnomic revision of $G$. orontii by Braun et al. 2019, has revealed several well supported and genetically distinct clades apart from $G$. orontii s. str. In their study, $G$. orontii isolates from different host plant species were segregated in to four species clades, namely G. tabaci (group 1), G. orontii s. str. (group 2), G. bolayi (group 3) and G. vinacae. Golovinomyces bolayi has been recorded from Asteraceae (Cichorieae, Cichorium and Lactuca spp.) based on its both asexual and sexual morphs; while, phylogenetically examined and proven host records (only asexual morphs) for this species are much wider (Braun et al. 2019).

A phylogeny based on ITS sequence data obtained in this study together with sequences obtained from GenBank grouped our sequence in a clade composed of Golovinomyces
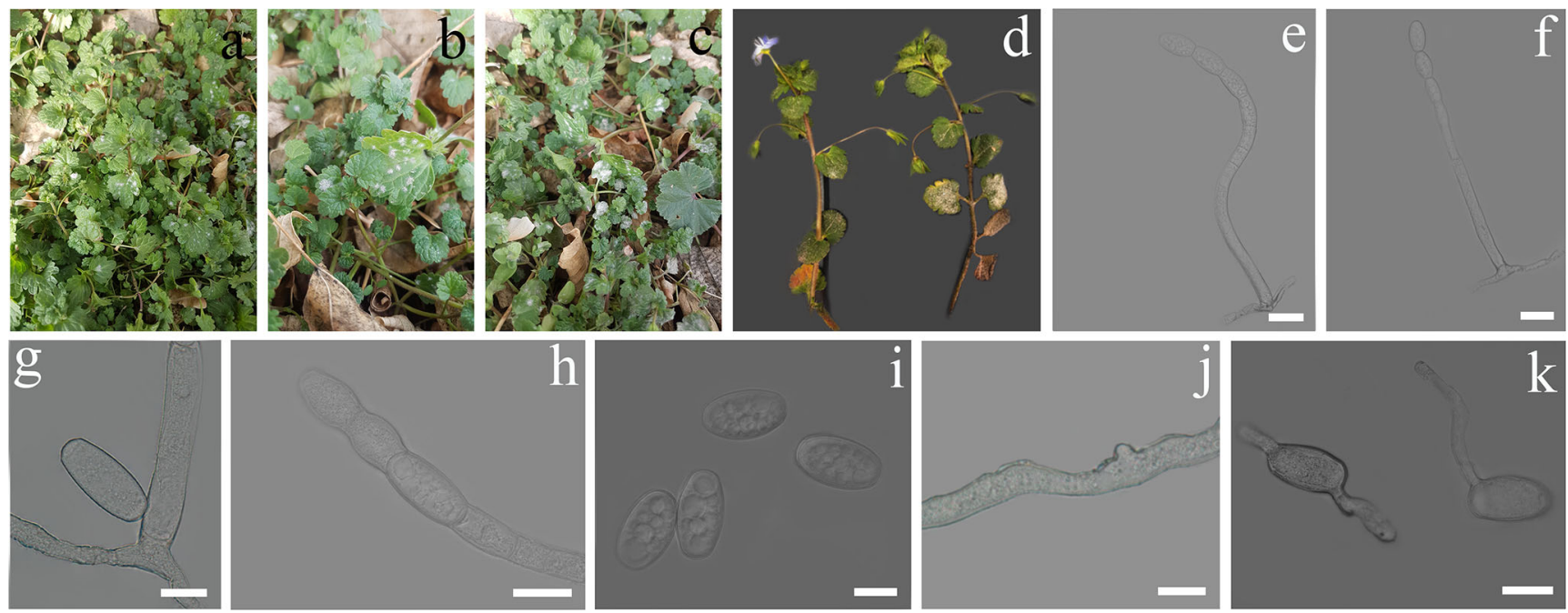

Fig. 1 Powdery mildew on Persian speedwell (Veronica persica) and Golovinomyces bolayi. a-d disease symptoms on leaves and flowers. e-h conidiophores and conidial chains. $\mathbf{i}$ conidia. $\mathbf{j}$ nipple-shaped appressoria. $\mathbf{k}$ euoidium type conidial germination pattern. Scale: $(\mathbf{e}-\mathbf{k})=10 \mu \mathrm{m}$ 
Fig. 2 Bayesian inference phylogenetic tree of Golovinomyces bolayi generated using sequences of internal transcribed spacer (ITS-rDNA). The sequence generated in this study is shown in bold face. The values above branches show Bayesian posterior probability. The scale bar indicates the number of expected substitutions per site. Arthrocladiella mougeotii (AB022380) was used as the out-group

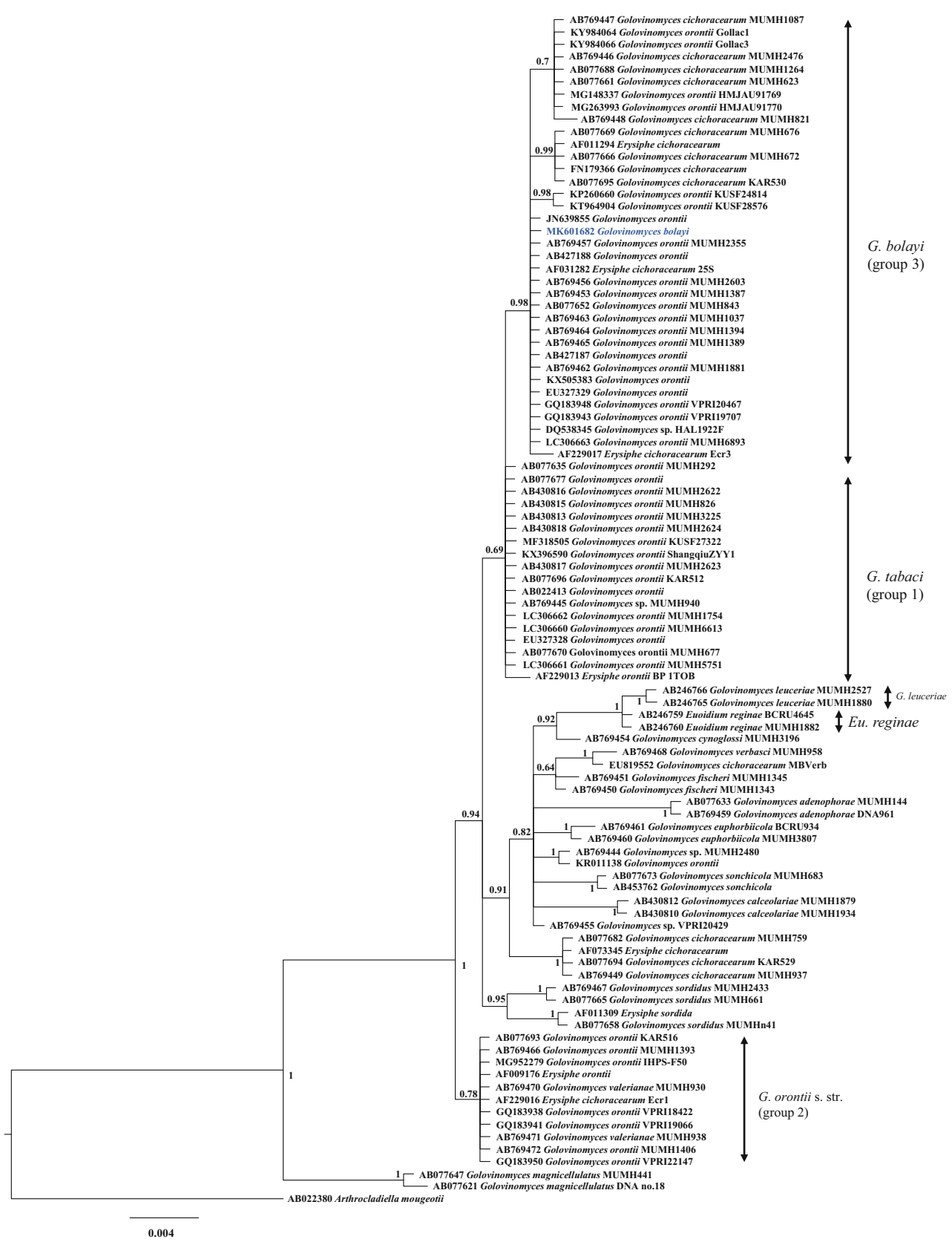

bolayi collections from different hosts including $V$. arvensis (JPN; AB077652) from Japan and Cymbalaria muralis (SWI; AB769464) from Switzerland, both residing in the family Plantaginaceae. (Fig. 2). Golovinomyces bolayi has been reported from Iran on Cichorium intybus and Lactuca sativa (Braun et al. 2019). To the best of our knowledge our study provides first occurrence of $G$. bolayi on Persian speedwell worldwide.

Acknowledgments We thank the Research Deputy of the University of Tabriz, for financial support of this research.

\section{References}

Arzanlou M, Torbati M, Golmohammadi H (2018) Powdery mildew on hazelnut (Corylus avellana) caused by Erysiphe corylacearum in Iran. Forest Pathol:e12450. https://doi.org/10.1111/efp.12450

Braun U, Cook RTA (2012) Taxonomic Manual of the Erysiphales (Powdery Mildews). CBS Biodiversity Series No. 11. CBS, Utrecht, The Netherlands

Braun U, Shin HD, Takamatsu S, Meeboon J, Kiss L, Lebeda A, Kitner M, Götz M (2019) Phylogeny and taxonomy of Golovinomyces orontii revisited. Mycol Prog 18:335-357

Matsuda S, Takamatsu S (2003) Evolution of host-parasite relationships of Golovinomyces (Ascomycete: Erysiphaceae) inferred from 
nuclear rDNA sequences. Mol Phylogenet Evol 27:314-327. https:// doi.org/10.1016/s1055-7903(02)00401-3

Nylander JAA (2004) MrModeltest v. 2.0. Program Distributed by the Author. Uppsala, Sweden, Evolutionary Biology Centre, Uppsala University

Ronquist F, Huelsenbeck JP (2003) MRBAYES 3: Bayesian phylogenetic inference under mixed models. Bioinformatics 19:1572-1574

Saeidi-Mehrvarz S, Zarrei M (2006) Pollen morphology of some species of the genus Veronica (Scrophulariaceae) in Iran. Wulfenia 13:1-9
Takamatsu S, Matsuda S, Grigaliunaite B (2013) Comprehensive phylogenetic analysis of the genus Golovinomyces (Ascomycota: erysiphales) reveals close evolutionary relationships with its host plants. Mycologia 105:1135-1152

White TJ, Bruns T, Lee S, Taylor JW (1990) Amplifcaton and direct sequencing of fungal ribosomal RNA genes for phylogenetcs. In: MA Innis, DH Gelfand, JJ Sninsky, TJ White (Eds.), PCR protocols: A guide to methods and applications (pp. 315-322). New York, NY, USA: Academic Press, Inc. 